\title{
"Propaganda aliada con exageraciones y falsificaciones". Racismo, antisemitismo y negacionismo en Julius Evola y sus lectores argentinos
}

\section{"Allied Propaganda with Exaggerations and Falsehoods." Racism, Antisemitism and Negationism in Julius Evola and his Argentinian followers}

\section{"Propaganda aliada com exagerações e falsificações". Racismo, anti-semitismo e negaçionismo em Julius Evola e seus leitores argentinos}

\author{
Boris Matías Grinchpun \\ Académico-investigador \\ Instituto de Historia Argentina y Americana Dr. Emilio Ravignani \\ Universidad de Buenos Aires/CONICET \\ Recibido: 4/5/2016 - Aceptado: 1/6/2016 \\ DOI: http://dx.doi.org/10.15359/tdn a.32-60.11
}

La palabra problema puede ser una insidiosa petición de principio. Hablar del «problema judio» es postular que los judios son un problema. Jorge Luis Borges, Otras Inquisiciones ${ }^{1}$

Resumen

Tras el final de la Segunda Guerra Mundial, Julius Evola regresó a Italia para brindar «orientaciones» a los

1 Borges, J.L. (1974). Obras Completas, 1923-1973. Buenos Aires: Emecé, p. 653.

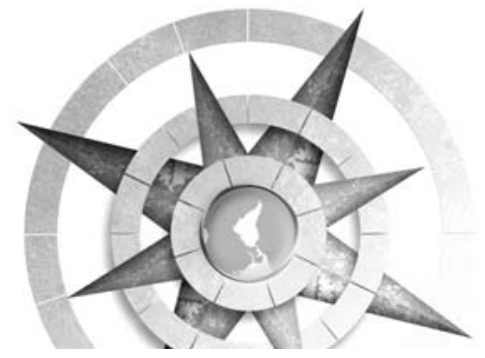

«hombres que se mantienen en pie entre las ruinas». Desde su apartamento romano, el aristócrata actuó como un pubblicista, difundiendo su pensamiento tradicionalista en libros y revistas. Una de sus estrategias consistió en diferenciarse de los regímenes caídos: discusiones sostenidas años antes con intelectuales «oficiales» fueron recuperadas por Evola para mostrar la superioridad de su doctrina. En esta línea, afirmó que su racismo era «espiritualista» en vez de «materialista» y «biologicista», por lo cual debía ser deslindado de los "científicos raciales», las persecuciones y los campos de exterminio. No obstante, el disenso tenía límites claros: el Barón Mágico no solo mantuvo su cosmovisión racista, sino que también reivindicó su acendrado antijudaísmo y adoptó posturas contradictorias frente al Holocausto. Estas ambivalencias se vieron 
reflejadas en los usos que, comenzando en los ochentas, varios círculos vinculados al perdurable nacionalismo argentino de derechas hicieron de Julius Evola. La circulación de su ideario antidemocrático y jerárquico desembocó en la aparición de El Fortín, la primera publicación local que se autoproclamó «evoliana». Desde sus páginas, los colaboradores articularon una visión "tradicional alternativa» de la política doméstica y la escena internacional. A partir de su caso, este artículo observará la recepción de Evola realizada por sus seguidores argentinos, al tiempo que considerará las derivas del racismo, el antisemitismo y el negacionismo en el nacionalismo de fines de siglo.

Palabras clave: antisemitismo, negacionismo, racismo, tradicionalismo, Evola, nacionalismo

\section{Abstract \\ After the end of the Second World War, Julius Evola returned to Italy to offer "ori- entamenti" to the "men who still stand amongst the ruins". From his Roman apartment, this aristocrat acted as a pub- blicista, spreading his traditionalist ideas through books and journals. One of his strategies consisted in differentiating him- self from the fallen regimes: discussions held years before with "official" intellectu- als were recovered by Evola as to prove the superiority of his doctrine. In this fashion, he stated that his racism was "spiritualist" instead of "materialist" and "biologicist", implying that it should be separated from the "racial scientists", the persecutions and the extermination camps. Howev- er, the distinction had clear limits: the}

"magical Baron" not only upheld his racist worldview, but also reaffirmed his deep-held antisemitism and adopted contradictory positions when considering the Holocaust. These ambiguities were reflected on the uses that, beginning in the 80's, some circles linked with the enduring Right-wing Argentinian nationalism made of Evola. The circulation of his ideas lead to the appearance of El Fortin, the first local publication which proclaimed itself "evolian". From its pages, the contributors articulated a "Traditional and alternative" view on domestic politics and the international arena. Through this case, this article will scrutinize how Evola was received by his Argentinian followers and will take into account, at the same time, how racism, antisemitism and negationism developed in end-of-century nationalism.

Keywords: Antisemitism, Negationism, Racism, Traditionalism, Evola, Nationalism

\section{Resumo}

Após o fim da segunda guerra mundial, Julius Evola retornou a Itália para dar "orientamenti" aos "homens que estão en pé entre as ruínas". De seu apartamento romano, este aristocrata atuou como um pubblicista, espalhando suas idéias tradicionalistas através de livros e revistas. Uma de suas estratégias consistiu em se diferenciar dos regimes caídos: discussões realizadas anos antes com intelectuais "oficiais" foram recuperadas por Evola para provar a superioridade de sua doutrina. Desta forma, ele afirmou que seu racismo era "espiritualista" em vez de "materialista" e "biologista", implicando que deveria ser

204 Propaganda aliada con exageraciones y falsificaciones... Boris Matías Grinchpun
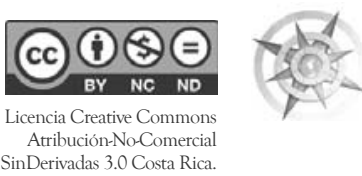
separado dos "cientistas raciais", das perseguições e dos campos de extermínio. Esta distinção tinha limites claros: o "Barão mágico" não só manteve sua cosmovisão racista, mas também reafirmou seu antissemitismo profundamente mantido e adotou posições contraditórias sobre $\mathrm{O}$ Holocausto. Essas ambiguidades se refletiram nos usos que, a partir dos anos 80 , alguns círculos ligados ao nacionalismo argentino de direita fizeram de Evola. A circulação de suas idéias levou à aparição de El Fortín, a primeira publicação local que se proclamou "evoliana". A partir de suas páginas, os autores articularam uma visão "tradicional e alternativa" sobre a política interna ea arena internacional. Este artigo examinará como Evola foi recebido por seus seguidores argentinos e, ao mesmo tempo, como o racismo, o anti-semitismo eo negacionismo se desenvolveram no nacionalismo do final do século.

Palavras chave: Semitismo, negação do Holocausto, racismo, tradicionalismo, Evola, nacionalismo.

\section{¿Revisar o reivindicar?}

A principios de la década de 1990, el músico noruego Kristen "Varg» Vikernes consideraba su pertenencia al nazismo como «algo natural». Incluso afirmaba que era «una lástima que el Holocausto [fuera] una mentira", (citado por Goodrick-Clarke, 2002: 205): para el fundador de Burzum destruir el mundo del judío era fundamental para la supervivencia de Europa. Vikernes, quien debía su fama a su participación en la quema de iglesias, sintetizaba una de las contradicciones presentes en los trabajos de los revisionistas: desmentir los relatos de los sobrevivientes y los análisis de los especialistas en nombre de la objetividad implicaba negar el exterminio de judíos, Roma y otros grupos étnicos y religiosos, perpetrado por los nazis y sus aliados, pero también comportaba una reivindicación. ${ }^{2}$

En efecto, ¿cuestionar documentos, memorias y un vasto corpus historiográfico no supondría aceptar, al menos en parte, la autorrepresentación del régimen nacionalsocialista y la narrativa de una cruzada contra el poder judío internacional (Cohn, 1988)? ¿No podría derivar en la reafirmación de la cosmovisión abiertamente racista que el Tercer Reich

2 Sobre la Solución Final existe una amplia bibliografía, entre la que pueden mencionarse Browing (2002). Aquellos Hombres Grises. El Batallón 101 y la Solución Final en Polonia. Madrid: Edhasa; Burrin (1995). Hitler et les Juifs. Genèse d'un génocide. París: La Seuil; Cesarini (2004). Holocaust. From the persecution of the Jews to mass murder. Londres: Routledge; Gellatelly (2002). Backing Hitler. Consent and coercion in Nazi Germany. Oxford: Oxford University Press; Goldhagen (1997). Los Verdugos Voluntarios de Hitler. Madrid: Taurus; Hilberg (2005). La Destrucción de los Judios Europeos. Madrid: Akal; y Longerich (2010). Holocaust. The Nazi persecution and murder of the Jews. Oxford: Oxford University Press.

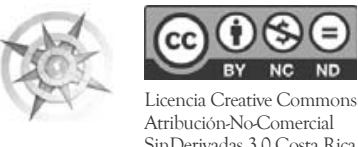

Propaganda aliada con exageraciones y falsificaciones... 205 Boris Matías Grinchpun 
configuró a través de su ideología y su maquinaria de propaganda? Las explicaciones de los negacionistas apuntarían en este sentido, en tanto manifestaban un desprecio apenas velado por aquello que denominaban como judio. ${ }^{3}$ De hecho, sostenían que la difusión de «exageraciones» y «mentiras» se explicaba por los beneficios económicos que grandes emporios obtenían gracias a ellas, por no mencionar su condición de fuente de legitimidad incontestable para el Estado de Israel. ${ }^{4}$

En un libro ya famoso, Deborah Lipstadt (1995) sostenía que la paradoja era solo aparente: no se trataba de una incongruencia, sino de un estudiado subterfugio. Detrás de la agenda de investigar con espíritu «imparcial», podía encontrarse una reivindicación

3 No se trata aquí de analizar el carácter «judaico» de los blancos de los negacionistas, lo que supondría aceptar las premisas de su discurso, sino de observar cómo este construye una versión propia de lo judío, la cual exhibe similitudes notables con el antisemitismo auspiciado por el Tercer Reich. Sin adoptar una perspectiva textualista, se presta atención al entorno simbólico que el propio discurso produce. Sobre este Umwelt, ver Palti (2009). El Momento Romántico. Buenos Aires: Eudeba.

4 Algunos de los ejemplos más sobresalientes del negacionismo son las obras de Austin App (1973), Arthur Butz (1976); Robert Faurisson (1980), Jürgen Graf (2007) y David Irving (2000). de los jerarcas nazis y una imagen distorsionada de su Gobierno. La historiadora coincidía en este punto con otros estudiosos, quienes señalaron las filiaciones de los negacionistas con agrupaciones de extrema derecha. ${ }^{5} \mathrm{La}$ afinidad política e ideológica encontraría expresiones institucionales y editoriales, como el Institute for Historical Review o la casa Samisdat Publications, del platillista Ernst Zündel (Goodrick-Clarke, 2002). En otras palabras, la «objetividad» no habría sido más que el pretexto para cuestionar un consenso establecido a lo largo de décadas de estudios académicos. Operación que incluiría una defensa, mayormente implícita, de movimientos desacreditados después de las experiencias de la guerra total y del exterminio racial sistemático en Europa.

Este negacionismo radical reconoce antecedentes en análisis que no cuestionaban necesariamente la veracidad de las matanzas, pero sí pretendían minimizar su magnitud o relativizar sus consecuencias. Fue este revisionismo, surgido durante la inmediata posguerra, el que cuestionó por primera vez la historia oficial y planteó muchas de las preguntas que, décadas después, autores como el polémico David

5 Entre la historiografía del negacionismo pueden señalarse los estudios de Roger Eatwell (1995), Richard Evans (2001); Gill Seidel (1986) y Pierre Vidal-Naquet (1994).

206 Propaganda aliada con exageraciones y falsificaciones... Boris Matías Grinchpun
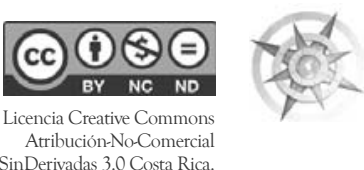
Irving todavía se empeñaban en responder (Lipstadt, 1995). Recién en los setentas, mientras los recuerdos de la traumática conflagración se transformaban con la distancia y la derecha radical se reorganizaba en Europa y América, la negación sumó suficientes adeptos como para dejar atrás los viejos matices y manifestarse en un flujo considerable de libros y artículos.

Las etapas de este despliegue deberían ser tenidas en cuenta a la hora de abordar los vínculos entre el negacionismo y Julius Evola. Si bien este aristócrata italiano no prestó mayor atención al revisionismo, se hizo eco de sus posturas al abordar el tópico durante los años cincuenta y sesenta. Sus opiniones revisten interés en tanto él se volvería un personaje de relieve en el panorama de las derechas, gracias a las numerosas traducciones de sus obras, los núcleos organizados para estudiar su pensamiento y la plétora de sitios web dedicados a su figura. ${ }^{6}$ Además, Evola escribió exten-

6 Sobre la influencia de Evola en las derechas durante la segunda posguerra ver Coogan (2000). Dreamer of the Day. Francis Parkey Yockey and the postwar fascist international. Nueva York, NY: Autonomedia; Ferraresi (1996). Threats to Democracy. The radical right in Italy after the war. Princeton, NJ: Princeton University Press; Goodrick-Clarke (2002). Black Sun. Aryan cults, esoteric nazism and the politics of identity. Nueva York, NY: New York University Press; Gregor (2006). The Search for Neofascism. The use and abuse of social science. samente sobre el racismo y el judaísmo antes de la conflagración, por lo cual su caso permitiría ver las continuidades y rupturas en estos tópicos antes y después de 1945.

La influencia de este autor ha alcanzado también a la Argentina, donde ha imbuido una de las manifestaciones más recientes del perdurable nacionalismo de derechas: el Centro Evoliano de América (CEDA), previamente conocido como Centro de Estudios Evolianos. Esta iniciativa, de carácter intelectual y doctrinario, se ve acompañada por la prédica antidemocrática esgrimida desde el periódico El Fortín y por la traducción de títulos tradicionalistas realizada por la Editorial Heracles. ${ }^{7}$ Tanto en la hoja del «Pensamiento Tradicional Alternativo" como en los volúmenes pueden encontrarse desplegadas las teorías racistas del mentor italiano, así como una persistente desconfianza hacia la versión oficial sobre lo ocurrido con

Cambrigde: Cambridge University Press; y Sedgwick (2004). Against the Modern World. Traditionalism and the secret intellectual history of the Twentieth Century. Nueva York, NY: Oxford University Press.).

7 Entre los escasos trabajos que se aproximaron a este grupo, generalmente de manera superficial, puede verse Kollman (2001). Sombras de Hitler. La vida secreta de las bandas neonazis argentinas. Buenos Aires: Sudamericana; y Sebreli (2002). Crítica de las Ideas Políticas Argentinas. Buenos Aires: Sudamericana.

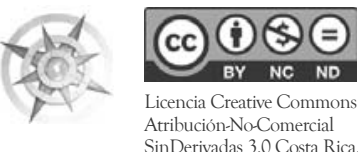

Propaganda aliada con exageraciones y falsificaciones... 207 Boris Matías Grinchpun 
los judíos europeos bajo el Nuevo Orden. Sin embargo, los evolianos han rechazado reiteradamente el mote de antisemitas: mucho habría de respetable en lo que designan como judaísmo tradicional, mientras que sus manifestaciones "modernas» serían reprobables, al igual que las políticas del Estado de Israel. ¿Es este antisionismo el encubrimiento de un ya conocido antisemitismo, como argumentaba Lipstadt, o representa un cambio en el discurso nacionalista? ¿Puede tomarse al revisionismo de El Fortín como una proyección de las posiciones de Evola, o ha contraído también una deuda con negacionistas más recientes y mejor conocidos?

Para responder a estas preguntas, este trabajo se dividirá en dos partes. La primera se aproximará al caso de Evola y repasará sus escritos sobre el racismo y la «cuestión judía» durante los años treinta, para luego explorar su regreso a la temática durante los años de posguerra. La segunda se focalizará en las páginas de El Fortín para recuperar las visiones presentadas sobre el judaísmo en general y sobre la campaña de extermino perpetrada por los nazis en particular. Así, se apuntará a definir los rasgos del racismo y el negacionismo expresados por el CEDA, analizar sus puntos de contacto y diferencias con el mentor italiano y analizar en qué medida representó un cambio en el campo discursivo del nacionalismo argentino de derechas.

\section{Entre los engaños aliados y los excesos nazis}

En su autobiografía intelectual, Il Cammino del Cinabro (1963), Julius Evola sostenía que su interés por «la cuestión de la raza» había surgido con el ascenso del nazismo, el cual había puesto en boga teorías que tildaba de materialistas y biologicistas. Trabajos como El mito del siglo veinte, de Alfred Rosenberg (1930), le merecían el mismo juicio que a León Trotsky: exhibían «una especie de racismo zoológico» (Evola, 2009: 165). No obstante, este tipo de planteos ganó numerosos adeptos, por lo cual el aristócrata se empeñó en presentar sus objeciones en sus libros y en revistas «especializadas». Violando ligeramente el pacto autobiográfico (Lejeune, 1975), podría señalarse que el tópico ya había aparecido en trabajos anteriores a 1933. De hecho, el racismo no era una simple reacción, sino un elemento central en su pensamiento.

En Imperialismo pagano (1928), el aristócrata explicaba la caída del Imperio romano a partir de la irrupción de una «ola semítica, oscura y bárbara, enemiga de sí misma y del mundo» que había sido «veneno para la grandeza de Roma» y una «sustancia galvanizadora

208 Propaganda aliada con exageraciones y falsificaciones... Boris Matías Grinchpun
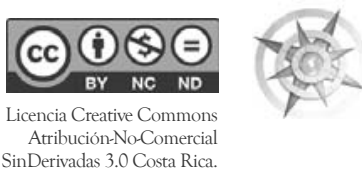
para todos los factores asiáticos-meridionales de la decadencia» (Evola, 2001: 29). Poco después, el barón inició una polémica contra las explicaciones en boga del otro lado de los Alpes: mientras el nazismo se fortalecía, este autor criticaba la exaltación biológica y física de las razas tildándola de democracia de la sangre. Extender cualidades nobles y «superiores» a «la plebe» era peligroso, ya que haría del racismo una fuerza igualadora. Los principios edificantes de la estirpe, por el contrario, se expresarían de forma pura solo en una minoría selecta y en su líder, los cuales cumplirían el rol de guías espirituales, jefes militares y soberanos (Germinario, 2001).

Este elitismo racialista se profundizaría a lo largo de la década, durante la cual Evola profundizó sus investigaciones. Así, en su magnum opus de 1934, Rivolta contro il Mondo Moderno, las razas cumplían un rol central en la macronarrativa que llevaba desde las civilizaciones de la tradición imperantes durante la Edad de Oro hasta las decadentes sociedades de masas del mundo moderno (Evola, 1969). Al estudiar este devenir, el autor privilegiaba los relatos míticos por sobre los documentos históricos, en lo que podría ser visto como una de las deudas contraídas con el pensamiento de Friedrich Nietzsche (Nietzsche, 1992).
La importancia del mito se expresaba en la morfología de civilizaciones presentada, la cual hacía uso de los continentes perdidos popularizados por Helena P. Blavatsky, como Hiperbórea y Lemuria, de la Atlántida platónica y de los titanes de Hesíodo, los cuales funcionaban como argumentos para refutar la teoría de la evolución y presentar una explicación inversa (Sprague de Camp, 1970). En efecto, «si el hombre moderno hasta ayer había concebido y exaltado como una evolución el sentido de la historia por él percibida, la verdad conocida por el hombre tradicional era la opuesta» es decir "la idea de un regreso, de una caída» (Evola, 1969: 222). Este declive se habría expresado en la degeneración y desaparición de pueblos «superiores», «más-que-humanos», quienes habrían dejado su lugar a grupos cada vez más alejados de las raíces «divinas», hasta llegar al hombre burgués, el exponente típico de la degenerada humanidad contemporánea.

Esta mutación podía resumirse como el paso de un polo axiológicamente positivo a uno negativo manifestado en una serie de pares opuestos que no solo estructuraba Rivolta contro il Mondo Moderno, sino el mismo pensamiento de Evola: lo superior contrapuesto a lo inferior, el Norte al Sur, lo solar a lo lunar, lo masculino a lo

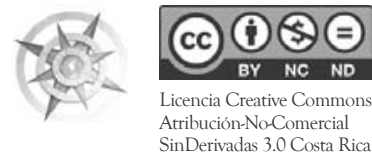

Propaganda aliada con exageraciones y falsificaciones... 209 Boris Matías Grinchpun 
femenino, la vida activa del guerrero a la contemplativa del sacerdote. El debilitamiento de un principio y el correspondiente fortalecimiento de su contrario eran los motores del declive, no las cruzas raciales o las migraciones. Asimismo, la dimensión ideal determinaba a la material, lo cultural a lo natural, por lo que en una misma estirpe espiritual podían encontrarse dos razas, con características físicas y mentales diferentes, pero cosmovisiones semejantes (Evola, 1969). A partir de esta premisa, el aristócrata elaboraba una vasta taxonomía de pueblos, cada uno de los cuales expresaba una combinación particular de principios materiales e ideales determinantes. Este esquema incluía referencias mitológicas, como el «demetrismo, como pureza de la Luz del Sur (edad de la plata, ciclo atlántico, sociedad sacerdotal)» y el «titanismo (...) como degeneración de la Luz del Norte (edad de bronce, era de los guerreros y los gigantes)» pero también a colectivos históricos, como egipcios, babilonios y romanos. (Evola, 1969: 280-292).

Al tiempo que desarrollaba su teoría macrohistórica, Evola exponía sus hipótesis raciales en las revistas del régimen. Escribiendo para Bibliografia Fascista en 1934, reconocía en el racismo nacionalsocialista una sana «reacción en contra de la concepción democrático-masónica de todos los hombres, en contra del ideal iluminista-racionalista y en gran medida pacifista de "principios inmortales válidos para todos"» (Evola, 2005:200), aunque apuntó que se trataba del «producto de una desviación, en sentido biológico-naturalista y también colectivista». Al creer en el "fatalismo» de los genes, este racismo caía en una zootecnia ingenua que equiparaba al ser humano con los animales. Para probar este error, Evola un término que tenía un rol mítico en el Tercer Reich:

«Ariano» o «ario» es la consigna del racismo, la que designa a la raza dominadora, la verdadera raza pura en un $100 \%$... a pesar de que prácticamente hoy en Alemania la cualidad «ariana» se reduzca a un simple concepto negativo, es decir al hecho de no ser judío, ni de raza de color. Pero de acuerdo a la concepción originaria, ârya queda como sinónimo de dvija, que quiere decir en sánscrito, «regenerado» o «nacidos dos veces» (Evola, 2005: 200).

Convertirse en ario implicaba atravesar un proceso iniciático limitado a unos pocos elegidos, de ahí que el aristócrata concluyera que «ârya designaba esencialmente a una "raza del espíritu”" (Evola, 2005: 200). A pesar de las referencias a la India védica, la noción no habría provenido de la «tradición» primigenia, sino del pensador

210 Propaganda aliada con exageraciones y falsificaciones... Boris Matías Grinchpun
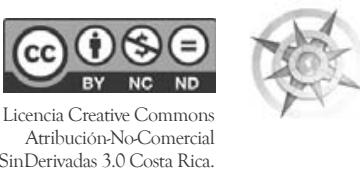
austríaco Otto Weininger. Su libro Geschlecht und Charakter (Sexo y carácter, 1903), popularizado en parte por el temprano suicidio de su autor, argumentaba entre otras cosas contra una determinación biológica de la personalidad (Coogan, 1999; Gillette, 2002).

La «raza del espíritu» no se alejaría de las reflexiones de Evola. El creciente interés por parte del régimen y de franjas del mercado lector explicaría que en 1937 la editorial Hoepli le encargara una "historia del racismo». El resultado sería Il Mito del Sangue, estudio de las doctrinas raciales en el "Mundo de la Tradición" con una perspectiva crítica de los escritos de Arthur de Gobineau, Houston Stewart Chamberlain y Rosenberg, entre otros (Evola, 2006a). La obra reproducía cuestiones ya tratadas, como el mito polar y las tipologías basadas en la raza, aunque enfatizaba aún más el carácter espiritualista del tradicionalismo y esbozaba, a partir del mismo, una doctrina «en tres grados».

El barón ampliaría este planteo durante los años siguientes, escribiendo en revistas como La Vita Italiana, de Giovanni Preziosi, o La Difesa della Razza, vinculada a los racistas biológicos (Gillette, 2002). La investigación culminaría en un manual, Sintesi della Dottrina della Razza, donde se afirmaba que en cada persona podía encontrarse una "raza del cuerpo», una del «alma» y una del «espíritu» (Evola, 2006), y que era sumamente extraña la coincidencia entre los tres co-principios. En otras palabras, la pureza racial era la conquista de una elite, no un rasgo de naciones enteras. A cada grado racial le correspondía una doctrina específica: la del primero se concentraba en los aspectos corpóreos, biológicos y antropológicos; la del segundo, focalizada en el alma, prestaba atención al «constante modo de ser o "estilo" en el orden de la acción, el pensamiento y el modo de sentir»; finalmente, la del tercero se concentraba en las razas del espíritu, lo que «comunica ya con fuerzas suprapersonales, superétnicas, metafísicas» y trascendentes (Evola, 2006: 113). ${ }^{8}$

En línea con las opiniones que venía desplegando desde mediados de los años veinte, el barón ponía a esta última dimensión espiritual en el lugar central, en tanto:

de aquello que es condicionado por el tiempo y por la historia y que, por ende, podría dar lugar solo a exhumaciones no vividas, casi a "conmemoraciones»,

8 El concepto de alma racial había sido tomado por Evola del antropólogo alemán Ludwig Clauss, cuyas teorías fueron bien recibidas durante el Tercer Reich. Véase Rees, 1990.

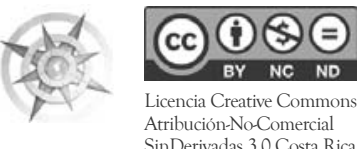

Propaganda aliada con exageraciones y falsificaciones... 211 Boris Matías Grinchpun 
se pasa al orden de aquello que, siendo esencialmente atemporal, no debe considerarse de «ayer»... sino de perenne actualidad: la raza eterna (Evola, 2006: 116).

Lo novedoso no era tanto el planteo como la explicitación de métodos como la frenología o la fisiognómica para el estudio de las razas, lo que hablaría de la pretensión de presentar una disciplina científica para el fascismo. De hecho, Evola presentó ese mismo año un estudio con directivas para una educación racista (Evola, 1979). Sin embargo, después de unos gestos favorables del Ministerio de Cultura Popular y del propio Mussolini, también estas ambiciones se verían frustradas (Evola, 2009; Gillette, 2002).

Siguiendo a Anthony James Gregor, podría pensarse que este fracaso era típico en la trayectoria del autor. Sus intentos por adquirir centralidad entre los elencos culturales del régimen se habrían visto frustrados por su propia ambigüedad frente al fascismo, su carácter ajeno a la academia y por la hostilidad (muchas veces reciprocada) de varios intelectuales y de instituciones relevantes como la Iglesia (Gregor, 2005). Germinario, siguiendo a George Mosse, ha planteado la tesis opuesta:

«Leemos en la deriva teórico-política evoliana, en particular en la elaboración de posiciones antisemitas y en el enfrentamiento con el nazismo, el despliegue de la ideología del fascismo maduro, o sea del fascismo en la fase de construcción del régimen totalitario» (Germinario, 2001: 22).

Para el historiador, "la evoliana fue una voz interna al régimen fascista: una voz que veía en el totalitarismo fascista una senda para la restauración de la sociedad tradicional» ( $p$. 22). Régimen que habría sido polifónico, aún en una cuestión tardíamente incorporada como el racismo. Y en ese campo, la voz de Evola habría sido una entre muchas: coyunturalmente influyente, pero por lo general no escuchada ni particularmente respetada (Gillette, 2002).

Además de su marginalidad o centralidad, el propio racismo de Julius Evola ha sido objeto de debate. En un estudio ya clásico Renzo de Felice había diferenciado a este aristócrata de figuras como Guido Landra, en tanto no se había dejado llevar por las mentiras ni el insulto. Por el contrario, habría actuado "con dignidad y hasta con seriedad» (De Felice, 1962: 447). Las réplicas no tardarían en llegar: Delio Cantimori reconoció que la figura tenía "peso e importancia», pero «valor, si en el término está implícito algún juicio en sentido positivo, no me parece» (Jesi, 1979: 98-99). 
Norberto Bobbio sostendría años después que Evola era un ejemplar «delirante» de los «intelectuales orgánicamente fascistas», generalmente "mediocres" y nunca tomados en serio (2008: 139). Opinión similar a la de Furio Jesi: «No basta, de hecho, declararlo un racista tan inmundo que repugna tocarlo con los dedos (lo que es verdadero) y tan insulso que no vale la pena dedicarle atención alguna (lo que no es verdadero) (1979: 97). Y esa atención no debía ser excesiva, ya que "también para los celebradores de la cultura por la cultura misma, Evola no debería poseer una gran aureola. Tendría, sí, el atractivo de las curiosidades culturales extravagantes» (p. 107).

No mucho más benevolente fue Umberto Eco, quien lo definió como una «triste e insensata figura» que «la Nueva Derecha ha repropuesto como un pensador de rango, mientras algunos imbéciles de la nueva izquierda han concedido que... tenía algunas cualidades» (Eco, 1997: 4). La polémica continúa hasta la actualidad, como lo ha mostrado la reciente conmemoración del cuadragésimo aniversario de la muerte de quien Giorgio Almirante apodara «nuestro Marcuse, pero mejor». (Coogan, 1999: 213).

Un agravante sería su marcado antisemitismo: en la Rivolta, un acápite entero era dedicado a describir el «Ciclo Hebreo», la antítesis de las "civilizaciones arias». En este sentido, «un tema característico y fundamental» de la raza hebrea sería «la transformación en pecado de aquello que en la forma aria del mito aparece como una audacia heroica frecuentemente coronada por el éxito». La consecuencia era una actitud sumisa, «un santo temor hacia un dios terrible, celoso y omnipotente: sin nada mejor que esperar, al final, que un "redentor" que producirá el rescate del exterior» (Evola, 1969: 295). El barón hallaba una explicación «histórica» para estos rasgos perniciosos: la Torá, forjada por la casta sacerdotal como un instrumento para unificar a un pueblo fragmentado y heteróclito, habría dado lugar a un «formalismo ritualístico» en materia religiosa y a una actitud abstracta hacia la vida. Allí estaría el origen de la especulación científica que se muestra «intolerante y se siente insatisfecha frente a todo orden positivo existente y a toda forma de autoridad», razón por la cual «es un continuo fermento de agitación y de revolución» (Evola, 1969: 297).

Apelando nuevamente a la mitología griega, el aristócrata hablaba de una raza «tifónica», hija del «ente enemigo del dios solar» que representaba «un espíritu demoníaco de agitación incesante, de contaminación oscura, de revuelta latente de los elementos

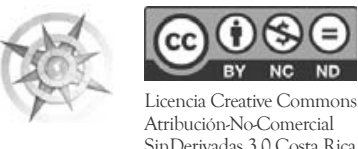

Propaganda aliada con exageraciones y falsificaciones... 213 Boris Matías Grinchpun 
inferiores, que en la sustancia hebraica actuó mucho más decididamente que en otros pueblos» (Evola, 1969: 297-298).

El aristócrata retornaría a la cuestión judía en Il Mito del Sangue y la Sintesi, tras publicar un estudio específico en 1936. Se trataba de un breve opúsculo titulado Tre Aspetti del Problema Ebraico, el cual se abría insistiendo sobre la importancia de los estudios racistas en Italia. Según Evola, solo en ese país el "problema» podría ser estudiado de manera objetiva, ya que no era «muy sentido». Acto seguido, en un giro característico, sostenía que las investigaciones corrientes estaban mal orientadas: «El antisemitismo está hoy caracterizado por la falta de un punto de vista verdaderamente general, de las premisas doctrinales e históricas, necesarias para poder verdaderamente justificar, siguiendo un proceso deductivo, las actitudes antisemitas prácticas, esto es sociales y políticas» (Evola, 1993: 13).

Establecidas de esta manera la pertinencia y la legitimidad de su indagación, el autor abordaba tres aspectos: el primero era el espiritual, analizado desde la usual contraposición entre la «espiritualidad ariana» y la «semítica». Y, entre los semitas, el Barón distinguía a los hebreos, los hijos de Tifón que sacudían al decadente mundo moderno; su influencia podía verse

en lo más profundo de las ideologías culminantes en la mística de una humanidad servil colectivizada bajo los signos de la internacional tanto blanca como roja, o bien en el «romanticismo» del alma moderna (...) en su activismo espiritualmente destructor, en su ímpetu desarticulado (Evola, 1993: 23).

El aspecto cultural recién se habría manifestado cuando los judíos se emanciparon, frustrados tras generaciones de dispersión y de espera sin respuesta del Mesías. En ese momento, el «tenaz instinto» de destrucción «se disfraza, asume forma serpentina, deviene actividad oculta, subterránea». Influencia que tenía como instrumento predilecto al dinero, que culminaba en el «mammonismo, la deificación del dinero y de la riqueza» y el pragmatismo, actitud que «muestra ilusorio e injusto todo lo que para nosotros tiene valor ideal, resaltando en su lugar con carácter de única realidad aquello que hay de inferior, de sensual y de animal en la naturaleza humana» (Evola, 1993: 32). Una acción paralela ejercería el «germen racionalista judaico», que habría "fructificado a lo largo de la historia en una dirección despersonalizante, mecanicista, antirracista, anticualitativa». Era así que Evola podía presentar una larga lista de intelectuales, 
artistas y científicos judíos (de Freud a Schönberg, de Marx a Einstein) cuyas «contribuciones» habrían sido la destrucción de las instituciones y los valores superiores y tradicionales. (Evola, 1993: 33-34).

No obstante, el Barón no creía que una acción totalitaria debiera enfocarse en los hebreos. Para él, esto suponía tomar al todo por la parte y eludir el grueso del problema: «La verdad es que el Hebreo mismo sirve sólo como pretexto, que la lucha contra el Hebreo es a menudo una lucha contra estructuras generales propias a la civilización moderna en general» (Evola, 1993: 30). De hecho, tampoco existiría una conspiración global:

Lejos de adjudicar al pueblo hebreo la dirección consciente de un plan mundial, como dice un mito antisemita demasiado fantasioso, nosotros tendemos a ver, en cierto instinto hebreo de humillarse, degradarse y disolver, la fuerza, que en algunos momentos históricos, es utilizada en la realización de una trama mucho más vasta (1993: 37).

Esta desconfianza en la conspiración conducía a un análisis crítico de Los Protocolos de los Sabios de Sión, ${ }^{9}$ el cual abarcaba buena parte del capítulo de-

9 Sobre la fabricación de este libro y sus usos ver Taguieff (2004). Les Protocoles des Sages de Sion. Faux et usages d'un faux (I). Introduction dicado al aspecto económico-social. Si bien Evola asociaba el panfleto a una corriente extremista y generalizada, concedía que «el curso de la historia social y política de la Europa moderna parece responder efectivamente a los objetivos establecidos» en la obra (Evola, 1993: 43). Incluso aceptaba la tesis de que la «acción hebraica» podía asumir «formas que aparentemente pueden ser incluso opuestas, pero que de todas formas procederían de una voluntad única, y estarían ordenadas hacia la realización de un mismo fin» (Evola, 1993: 45). En este sentido, socialismo y capitalismo, pacifismo y militarismo, no serían más que aristas de un mismo mal. Pero este no sería exclusivamente judío:

Aquello que se debe verdaderamente combatir, no es tanto el hebreo propiamente dicho, sino una forma mentis que, si se quiere, puede por analogía ser llamada "hebraica», pero que no por esto deja de estar presente también donde no sería posible encontrar ni siquiera una gota de sangre semita (Evola, 1993:47).

Por ese motivo, la forma de antisemitismo nacionalista y racista que proponía no apelaba a la marginación de los judíos o la expulsión hacia algún lugar por determinar, sino a una difusa «restauración no artificial, sino

a l'etude des "Protocoles»: un faux et ses usages dans le siècle. París: Berg International.

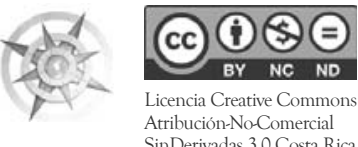

Propaganda aliada con exageraciones y falsificaciones... 215 Boris Matías Grinchpun 
austera y viviente» de «la Europa monárquico-aristocrática y heroica, la Europa jerárquica, diferenciada y espiritual» (Evola, 1993: 52).

A pesar de los extravíos, los Protocolos eran considerados valiosos: en diciembre de 1937 Evola insistía sobre su veracidad en un ensayo aparecido en La Vita Italiana..$^{10}$ Allí, el aristócrata afirmaba que los Protocolos podían no ser «auténticos», ya que ninguna sociedad secreta revelaba sus documentos, pero sí «veraces», en tanto «los hechos demuestran su verdad» y «responden indiscutiblemente a las ideas fundamentales del Hebraísmo tradicional y moderno» (Evola, 1988). Se trataría de una «hipótesis de trabajo (...) cuya verdad se reconfirma a través de su capacidad de organizar, en una investigación inductiva, un conjunto de hechos aparentemente esparcidos y espontáneos» (Evola, 1988: 10). La entusiasta defensa habría sido del agrado de Giovanni Preziosi, quien la convirtió en la introducción a la edición de los Protocolos que realizó en 1938.

Germinario ha sostenido que, a pesar de estos matices, el antisemitismo de Evola contenía muchos de los tópicos usuales: el judío estaba inclinado

10 El artículo se titulaba "La volontá di potenza e l'autenticitá dei 'Protocolli'", y apareció en La Vita Italiana, diciembre de 1937. Una crítica incisiva puede hallarse en Mattogno (1987). al pensamiento abstracto, al dinero, a los «atavismos» psicológicos y a las posiciones extremas y «corrosivas». Algunos elementos estarían ausentes, como la referencia a la usura o a los asesinatos rituales (Germinario, 2001). Estos estereotipos se reforzarían durante la guerra, a lo largo de la cual el aristócrata publicó recurrentemente artículos denostando la forma mentis hebraica, su influencia histórica y sus representantes (Evola, 2006). $\mathrm{Su}$ antisemitismo habría sobrevivido a la conflagración, ya que tanto Tre Aspetti del Problema Ebraico como el estudio preliminar de los Protocolos no fueron modificados en las sucesivas reediciones por Evola, bastante dado a hacer revisiones extensas de sus trabajos (Furlong, 2011).

Siendo todavía «un antisemita espiritual» en la posguerra, ¿cuál fue la reacción de este autor frente a la Solución Final? Resulta difícil ofrecer una respuesta unívoca, ya que el barón asumió posturas contradictorias. En 1959 reivindicó sus estudios racistas y negó que fueran «un simple sinónimo de antisemitismo, de Buchenwald, de cámaras de gas y todo lo demás que ha sido administrado por la propaganda aliada con un amplio uso de exageraciones y aún de falsedades [cursivas añadidas]» (Furlong, 2011: 124). Así, el habría estado cerca de los primeros revisionistas analizados por Lipstadt, quienes

216 Propaganda aliada con exageraciones y falsificaciones... Boris Matías Grinchpun
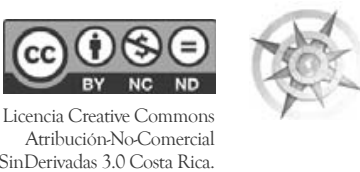
no negaron la existencia de los campos, pero sí relativizaron su alcance y denunciaron una operación de propaganda pergeñada por Gran Bretaña. Es probable que Evola hubiera leído algunas de las obras pioneras del negacionismo, como Nuremberg ou la Terre Promise de Maurice Bardeche (1948) o Le Mensonge d'Ulysse de Paul Rassinier (1950). De hecho, el aristócrata reseñó la voluminosa Imperium de Francis Parker Yockey (Varange, 1962), uno de los primeros cuestionamientos de la versión oficial (Coogan, 1999).

No obstante, en su autobiografía intelectual Evola criticaba el «vulgar antisemitismo» del Tercer Reich y aseveraba que «de más está decir que ni yo ni ninguno de mis amigos en Alemania sabíamos de los excesos nazis contra los judíos; de haber sabido de ellos, de ninguno manera los habríamos aprobado» (Evola, 2009: 178). Así, habría pretendido resguardar sus elucubraciones racistas y su persona de la pesada carga del Holocausto, algo esperable en un libro pensado para disipar las controversias generadas por Cavalcare la Tigre (1961). Pero aun así, como señala Germinario, el término excesos no abarca la dimensión del proceso de exterminio, sino que lo minimiza; al mismo tiempo, podría dudarse del completo desconocimiento por parte de un actor bien conectado con los círculos fascistas y nacionalsocialistas. Por no mencionar que los límites entre su doctrina y la nazi, si bien están presentes, se hacen por momentos borrosos: ambas posturas eran deterministas, ya que, sea por sus genes o por su espíritu, la persona se veía reducida, en última instancia, a su raza (Germinario, 2001). En esta línea, podría seguirse a Paul Furlong cuando plantea que la falta de un juicio claro y de autorreflexión crítica sugieren en Evola una «seria falta de comprensión de cuan radical había sido un acontecimiento como el Holocausto» (2011: 115).

\section{«Estamos con los palestinos, que son semitas" ${ }^{11}$}

El 2 de abril de 1985 hizo su primera aparición El Fortín, un mensuario nacionalista distribuido en la zona de Alto Valle, en la Patagonia. Como la fecha sugería, los colaboradores, entre los que se contaban Hugo Ramasco, Marcelo Verdugo y Marcos Ghio, hicieron del irredentismo por las Islas Malvinas uno de los núcleos centrales de su discurso. La publicación se orientó a contrarrestar un movimiento de opinión favorable a la secesión de la región, al tiempo que atacaban a la «democracia» en general y al Gobierno

11 Platicando con Goldfarb. En El Fortín № 8, octubre-noviembre, 1997.

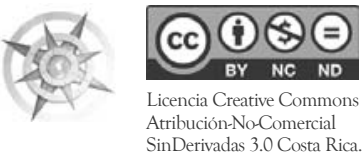

Propaganda aliada con exageraciones y falsificaciones... 217 Boris Matías Grinchpun 
de Raúl Alfonsín en particular. ${ }^{12}$ Poco hubo del tradicionalismo evoliano en esta hoja, la cual venció al secesionismo, pero se distanció progresivamente de otras expresiones políticas e intelectuales del nacionalismo.

La empresa se interrumpió en 1991 para ser retomada cuatro años después, cuando un grupo de redactores bajo la dirección de Ghio inauguró la tercera época de El Fortín, convertido en una «Publicación Nacionalista de Alternativa» que exaltaba abiertamente al «maestro» italiano. La revista, que pronto se volvió bimensual, publicó comentarios cáusticos sobre otras fuerzas de derecha (Cook, 1996; Ghio, 1995; Preziosi, 1998), artículos sobre la decadencia del sistema político argentino (Gargani, 1995; Ghio, 1999), denuncias de una amenaza anglo-estadounidense en el país (Baffi, 1996; Cook, 1995; Ghio, 1996) y crónicas de la ubicua corrupción del Mundo Moderno (Flores 1999; Gargani 1995; Ghio 1996).

El giro tradicionalista habría precedido al relanzamiento de El Fortin: un año antes, con motivo del vigésimo aniversario de la muerte del barón, Heracles había lanzado una traducción castellana de Rivolta contro il Mondo Moderno.

12 Una «historia oficial» puede encontrarse en Ghio, al cumplirse los treinta años de la publicación El Fortín. En El Fortin $N^{\circ}$ 76, octubre 2014-abril 2015. Recuperado www.juliusevola.com.ar/Fortin.htm
La tarea recayó sobre los hombros de Ghio, licenciado en Filosofía en la Universidad de Buenos Aires, quien, tras ser cesanteado en 1978, se mudó al sur del país donde se dedicó a la enseñanza media. Ya entonces tenía vínculos con el nacionalismo argentino de derechas, en particular con el grupo nucleado en la revista Cabildo y con Federico Ibarguren. ${ }^{13}$ A mediados de los ochentas, la lectura del Bhagavad-gītā lo habría conducido a la exploración de Evola, cuyo pensamiento comenzó a difundir a través de algunas revistas católicas y nacionalistas. ${ }^{14}$

Si bien Ghio no fue el primer lector del pensador tradicionalista en la Argentina, ni fue Heracles la primera casa en traducirlo al castellano, la creación de un sello editorial, una revista y un centro de estudios declaradamente evolianos no tenía precedentes. ${ }^{15}$

13 Breves referencias a esta figura pueden encontrarse en Kiernan (2006), Kollman (2001) y Sedgwick (2015). Ghio afrontó un proceso judicial por una supuesta reivindicación de las desapariciones durante el "Proceso", aunque fue finalmente absuelto. En su renuncia forzada al cargo docente en Neuquén, en 1994, podría hallarse una de las raíces de la nueva "época" de El Fortín.

14 M. Ghio (1986). René Guénon y Julius Evola: ¿crisis o revuelta contra el mundo moderno? Verbo $N^{\circ} 264$, s/p.

15 El Centro de Estudios Evolianos fue fundado en 1997, junto a un nuevo relanzamiento de la «Publicación Nacionalista de Alternativa». Ver Centro de Estudios

218 Propaganda aliada con exageraciones y falsificaciones...

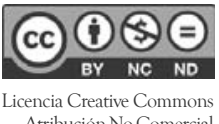
Boris Matías Grinchpun

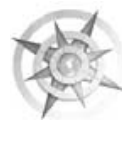


La labor fue incesante: a Rebelión contra el Mundo Moderno le siguieron Los Hombres y las Ruinas y Más Allá del Fascismo. Este último, una recopilación de escritos y ensayos donde Evola manifestaba sus diferencias con el régimen de Mussolini, apuntaría hacia una de las marcas de la recepción realizada por los discípulos argentinos: el tradicionalismo representaría una doctrina de derecha superadora en el plano teórico del fracasado nacionalismo vernáculo, pero también librada de la pesada herencia del totalitarismo. ${ }^{16}$ No obstante, la relación de El Fortín con esas dictaduras fue tan ambivalente como la entablada por su mentor italiano: las objeciones circunstanciales convivían con una recurrente reivindicación del fascismo en sus aspectos legionarios y heroicos (Evola, 1999: 8). Asimismo, los cincuenta años de la muerte del Duce motivaron un apoteósico homenaje, en el que se le presentaba como «uno de los hombres públicos más brillantes y dignos que ha dado la política europea en este siglo y hasta nos atreveríamos a decir en toda su historia» (Preziosi,

Evolianos (octubre-noviembre, 1997). El Fortín $\mathrm{N}^{\circ} 8$, p. 3

16 La segunda edición de Más Allá del Fascismo fue ampliada para incluir una traducción de las altamente «Notas sobre el Tercer Reich» escritas por el aristócrata italiano.Véase, Evola (2006). noviembre, 1995: 3) y se tildaba a su ejecución de «crimen deleznable».

No debería omitirse que el racismo espiritualista era una de las tramas centrales en el discurso de la revista: La Raza del Espíritu se sumó a la biblioteca de Heracles en 1996, y fue recibida con una elogiosa reseña de Walter Preziosi. El articulista reproducía las críticas de Evola al igualitarismo iluminista y al racismo biologicista para concluir que

Los seres humanos son pues desiguales esencialmente no en cuanto al cuerpo o al color de la piel, sino en tanto hay unos en quienes ha triunfado la raza de los que se gobiernan y determinan a sí mismos y [en] otros en cambio la de quienes son producidos y determinados por el medio (Preziosi, 1996: 8).

También Ghio recurría a concepciones racistas en su análisis de los orígenes de la nacionalidad argentina: «con la aparición del gaucho la raza católica española originaria se fortificó y adquirió un carácter indomable, extremadamente reacio hacia los cambios, más aún si provenientes del extranjero, y dispuesta incluso a morir antes que a doblegarse» (Ghio, octubre, 1995: 8). Al igual que Evola, el director de El Fortín intentaba refutar el racismo biológico señalando el valor potencialmente positivo de las «cruzas»: en este sentido, el gaucho sería

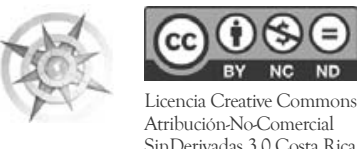

Propaganda aliada con exageraciones y falsificaciones... 219 Boris Matías Grinchpun 
el resultado de una «feliz mezcla de etnias» americanas y europeas, una «raza de guerreros» que tenía «el alma del animal de presa». (1995: 8)

Rastros del racismo evoliano podían hallarse también en una columna doctrinaria titulada "Metapolítica», en la que autores que utilizaban seudónimos presentaron una teoría que no se alejaba de los lineamientos establecidos por el autor tradicionalista: en el ser humano coexistirían dos estirpes, "una es la raza por excelencia puesto que en ella el Espíritu tiende a unirse a la Materia en una armonía perfecta”, mientras que la otra sería "la raza de la horda y del caos que brama ansiosamente perderse en las dimensiones ilusorias del tiempo y del espacio" (1996, 2-3). Asimismo, los columnistas se refirieron a la ya mencionada "Orden", contrapuesta favorablemente a los partidos políticos y definida como "la estructura tradicional arquetípica para los tiempos actuales de disolución” $(1995,8)$.

Si el racismo era tan explícito como en los escritos del aristócrata, el antisemitismo tampoco estaba ausente. Como reacción a la incautación de ejemplares de El Fortín de la Librería Huemul, Ghio publicó un encendido artículo donde responsabilizaba al embajador de Israel y a la Delegación de Asociaciones Israelitas Argentinas (DAIA) por lo ocurrido. Frente a las acusaciones de antisemitismo, el director aseveraba que «efectivamente somos antijudios». El motivo residía en que el judaísmo era

Una de las principales fuerzas disolventes de nuestra civilización, cuya acción corrosiva detectamos desde la misma Antigüedad (...) en su práctica y promoción clandestina de la usura durante toda la Edad Media y varios siglos de la Moderna, en su clara influencia en fenómenos decisorios y disolventes de nuestro tiempo (Ghio, 1996: 2).

No obstante, Ghio seguía fielmente los Tre Aspetti del Problema Ebraico al apuntar que el judío estaba acompañado por «el protestantismo, el iluminismo, el liberalismo, el marxismo, el cristianismo ecuménico, etc., los cuales, como brazos múltiples de una misma cabeza oculta, se dirigen por caminos distintos hacia un idéntico fin» (Ghio, 1996: 2). Concentrarse en los judíos era caer en una de las trampas del enemigo, la del chivo expiatorio.

El director llegaba incluso a rescatar las expresiones más tradicionales de la religión hebrea de la ignominia, aunque se descargaba con furia contra el sionismo. Este sería una "consecuencia exacerbada del judaísmo en su tendencia hacia la secularización de sus dogmas», lo que transformaría el concepto de pueblo elegido en «un racismo y un superimperialismo que se funda en la pretendida superioridad del judio sobre

220 Propaganda aliada con exageraciones y falsificaciones... Boris Matías Grinchpun
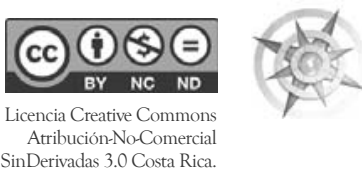
los otros pueblos y de lo cual los palestinos actualmente son las víctimas más ostensibles» [el énfasis es del original] (Ghio, El Fortín, 4 de abril, de 1996).

Fue así que en una aparición televisiva ocurrida años después Ghio pudo afirmar que él no era antisemita, ya que «estaba con los palestinos» (El Fortín, octubre-noviembre, 1997, p. 4). Como puede verse, el carácter pretendidamente analítico de nociones como antisionismo, antisemitismo y antijudaísmo cede frente a sus ribetes polémicos, por lo cual se dificulta establecer una diferencia estricta entre los mismos. ${ }^{17}$ Tal vez sea apropiado decir que se mezclan como definiciones alternativas de la posición de los evolianos, la cual reproduce viejos tópicos del nacionalismo argentino limando sus costados más ásperos.

En este sentido, el secuestro de la revista era visto como un motivo de orgullo para el director, quien también se complacía en marcar las diferencias entre

17 Basándose en el caso de Venezuela durante el Gobierno de Hugo Chávez, Graciela Ben Dror ha optado por tomar antisemitismo y antisionismo como sinónimos en términos discursivos y políticos. Aquí se plantea, por el contrario, que la diferencia entre ambos términos es discernible y posible, aunque política e ideológicamente puedan presentarse como fenómenos similares. Ver Graciela Ben Dror (diciembre, 2007). Entre el antisemitismo tradicional y el «nuevo antisemitismo» en América Latina. Nuestra Memoria, XIII(29). su «antijudaísmo» y el "panfletario antisemitismo» de cierto "nacionalismo anticlerical» (Ghio, marzo-abril, 1996).

Sin embargo, a El Fortin se le haría difícil liberarse del legado antisemita del nacionalismo argentino de derechas, perdurablemente fascinado por el mito de la conspiración judía (Lvovich, 2003). Meses después Marcos Ghio se mostraría indignado frente al secuestro en el mismo establecimiento de las obras de Gustavo Martínez Zuviría, celebrado como «insigne maestro de las letras argentinas» (Ghio, junio-julio, 1996, 1-2). La defensa del autor de El Kahal-Oro (Wast, 1975), seguidor entusiasta de los Protocolos, no se basó solo en su prestigio literario: se intentó también minimizar su antisemitismo señalando novelas ajenas al tema, o bien relativizarlo señalando la aversión por los judíos en El Mercader de Venecia (Ghio, junio-julio, 1996).

De todas maneras, los problemas legales habrían obligado a mitigar las referencias antijudaicas, como puede verse en el calendario de conferencias del centro de estudios. No obstante, los ataques reaparecieron a causa de los procesos iniciados contra el matrimonio Buela (distribuidor de películas del nacionalsocialismo y documentales revisionistas) y contra criminales de guerra como Herbert Habel, Dinko Sakic y Mirko Eterovich, los que fueron vistos

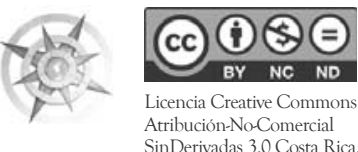

Propaganda aliada con exageraciones y falsificaciones... 221 Boris Matías Grinchpun 
como persecuciones sionistas contra personas fundamentalmente inocentes (Ghio, septiembre-octubre, 1999, 2-3).

Tanto los Buela como Habel habían expresado opiniones negacionistas o, por lo menos, reduccionistas. Postura que, por otra parte, encontraba un antecedente en las páginas de $\mathrm{C} a$ bildo (Saborido, 2011). ¿La compartía El Fortin? En su tercera época no puede hallarse una negación total de los crímenes nazis, pero sí un cuestionamiento de su escala que se fortaleció cuando el tabloide se convirtió en sitio web. Allí se habló del «llamado Holocausto» (Ghio, septiembre-noviembre, 2013). Este, al basarse en la idea de un crimen sin comparación posible, legitimaría al Estado de Israel, justificaría sus agresiones armadas y explicaría su ideología militarista. Al mismo tiempo, habría avanzado la agenda de los Protocolos, ya que se habría convertido «en la punta de lanza efectiva para establecer un dominio judio sobre las restantes naciones» (Ghio, noviembre-diciembre, 2008: s/p).

En este sentido, la hoja no se alejaría de los usos políticos que otros negacionistas encontraban en la "mentira" del Holocausto. No obstante, para el grupo de Ghio no se trataría de una mentira, sino de una exageración: en una nota solidaria con el negacionista catalán Pedro Varela Geiss, el director de El Fortín se hacía cómplice de la duda sobre el número de judíos asesinados en Auschwitz, apuntando la evolución demográfica durante la posguerra. El cuestionamiento no partiría del antisemitismo, sino de la simple aplicación del "principio metodológico de la objetividad científica» (Ghio, 2008).

Ghio no se alejaba aquí de Faurisson o de Irving, como tampoco lo haría al transformar a Varela en el victimario de una sociedad democrática hipócrita que no defendía en la práctica la libertad de expresión de la que tanto se vanagloriaba.

A modo de cierre, podría afirmarse que la recepción realizada por El Fortín del racismo evoliano reprodujo tanto las vetas espiritualistas del mismo como su marcado antijudaísmo. Si bien la publicación buscaba alejarse de otras variantes del nacionalismo vernáculo y cuestionar sus premisas, en materia de antisemitismo los efectos discursivos y prácticos de ambos no serían muy disímiles. La oposición al Estado de Israel y el apoyo a los palestinos, esgrimidos como atenuantes, no impedían la reproducción de trillados estereotipos negativos sobre los judíos, ni su conceptuación como raza tifónica. Esta animadversión habría sido terreno fértil para el surgimiento de un negacionismo que tampoco se

222 Propaganda aliada con exageraciones y falsificaciones... Boris Matías Grinchpun
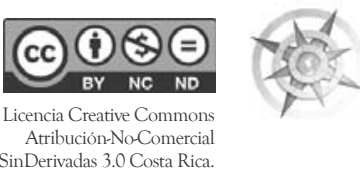
alejaba de Julius Evola: si bien se admitía la existencia de los hornos de Auschwitz, la magnitud del crimen sería una mentira interesada de consecuencias funestas. Reducción que no sería meramente cuantitativa, ya que llevaría aparejada la negación del carácter radical del Holocausto. Y tampoco se limitaría a la Solución Final, sino que haría referencia a otros crímenes de gran escala, incluidos los del Proceso de Reorganización Nacional. En este sentido, tal vez sería apropiado hablar de negacionismos, una de las armas de los hombres de la tradición en su guerra oculta contra el mundo moderno.

\section{Referencias}

Anónimo (1988). Los Protocolos de los Sabios de Sión. Buenos Aires: Temas Contemporáneos.

Anónimo ("Nigrus"). (Noviembre, 1995). La Orden (IV). Las dos razas El Fortín № 2.

Bardeche, M. (1948). Nuremberg ou la Terre Promise. París: Les Sept Couleurs.

Cohn, N. (1988). El Mito de la Conspiración Judia Mundial. Madrid: Alianza.

Coogan, K. (1999). Dreamer of the Day. Francis Parkey Yockey and the postwar fascist international. Nueva York, NY: Autonomedia.

De Felice, R. (1962). Storia degli Ebrei Italiani sotto il Fascismo. Turín: Einaudi.

Eco, U. (12 de abril, 1997). Julius Evola. L'Espresso, p. 4

Evola, J. (5 de junio, 1959). Razzismo e alti 'orrori' (compreso il Ghibellinismo). L'Italiano. (1961). Cavalcare la tigre. Milan: Vanni Scheiwiller.

(1969). Rivolta contro il Mondo Moderno. Roma: Edizioni Mediterranee.
(1979). Indirizzi per una Educazione Razziale. Padúa: Edizioni di Ar. . (1988). Introducción a Los Protocolos de los Sabios de Sión. En Anónimo, Los Protocolos de los Sabios de Sión. Buenos Aires: Temas Contemporáneos. . (1993). Tre Aspetti del Problema Ebraico. Padua: Edizioni di Ar. (1999). Mi encuentro con Codreanu. El Fortin No 13, p. 8 . (2001). [1928 original italiano]. Imperialismo pagano. Buenos $\mathrm{Ai}$ res: Heracles. (2005). [1941 original italiano]. La raza del espíritu. Buenos Aires: Heracles.

(2006a). [1937 original italiano]. El Mito de la Sangre. Buenos Aires: Heracles.

(2006b). Escritos sobre el Judaismo. Buenos Aires: Heracles. (2009). [1963 original italiano]. The Path of Cinnabar. Londres: Integral Tradition Publishing.

Furlong, P. (2011). Social and Political Thought of Julius Evola. Nueva York, NY: Routledge.

Germinario, F. (2001). Razza del Sangue, Razza dello Spirito. Julius Evola, l'antisemitismo e il nazionalsocialismo (1930-43). Turín: Bollati Boringhieri.

Ghio, M. (Octubre, 1995). Julius Evola y el nacionalismo argentino. El Fortín No 1, pp. 6-8.

. (Marzo-abril, 1996). Crónica acerca de judíos, secuestros y calumnias. El Fortín No 4, p. 2

(Junio-julio, 1996). Indicaciones para fiscales que «investigan». El Fortin № 5, pp. 1-2.

(Septiembre-octubre, 1999). Siguen las persecuciones sionistas. El Fortin No 13, pp. 2-3

(Noviembre-diciembre, 2008). La industria del Holocausto. El Fortín No 44. Recuperado de www.juliusevola.

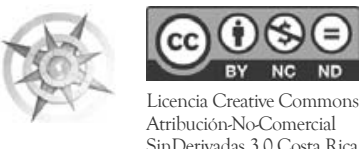

Propaganda aliada con exageraciones y falsificaciones... 223 Boris Matías Grinchpun 
com.ar/Fortin.htm. (Septiembre-noviembre, 2013). Relaciones entre nazismo y sionismo. Ana Arendt en Jerusalén. El Fortín № 71. Recuperado de www.juliusevola.com.ar/Fortin.htm

Gillette, A. (2002). Racial Theories in Fascist Italy. Nueva York, NY: Routledge.

Goodrick-Clarke, N. (2002). Black Sun. Aryan cults, esoteric nazism and the politics of identity. Nueva York, NY: New York University Press.

Gregor, A. (2005). Mussolini's Intellectuals. Fascist social and political thought. Princeton, NJ: Princeton University Press.

Jesi, F. (1979). Cultura di Destra. Milán: Aldo Garzanti Editore.

Lejeune, P. (1975). Le Pacte Autobiographique. París: Seuil.

Lipstadt, D. (1995). Denying the Holocaust. The growing assault on truth and memory. Nueva York, NY: Plume.

Los Dioscuros (Seud.). La Orden (IV). (Junio-julio, 1996). Las dos razas. El Fortin No 5, p. $2-3$

Lvovich, D. (2003). Nacionalismo y antisemitismo en la Argentina. Buenos Aires: Ediciones B.
Nietzsche, F. (1992). Consideraciones intempestivas. Buenos Aires: Alianza.

Platicando con Goldfarb (octubre-noviembre, 1997). El Fortín No 8, p. 1-4

Preziosi, W. (Noviembre, 1995). A cincuenta años de un crimen deleznable. El For$\operatorname{tin} \mathrm{N}^{\circ} 2$, p. 2-3.

. (Agosto-septiembre, 1996). Una nueva obra fundamental de Julius Evola. El Fortín No 6, p. 8.

Rassinier, P. (1998) Le Mensonge d'Ulysse. París: Ulysse.

Rossi, S. (2007). Il Razzista Totalitario. Evola e la leggenda dell'antisemitismo spirituale. Roma: Rubbettino.

Saborido, J. (2011). «Por la Nación contra el Caos». La revista Cabildo y el Proceso de Reorganización Nacional. En M. Borre-1li y J. Saborido (coords.), Voces y Silen-cios. La prensa argentina y la dictadura mi-litar (1976-1983). Buenos Aires: Eudeba.

Sprague de Camp, L. (1970). Lost Continents. The Atlantis theme in history, science and literature. Nueva York, NY: Dover Publications.

Varange, U. (Francis Parker Yockey). (1962).

Imperium. The Philosophy of history and poli-

tics. Sausalito, CA: The Noontide Press.

224 Propaganda aliada con exageraciones y falsificaciones... Boris Matías Grinchpun
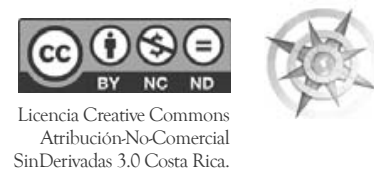